2016-10-15

\title{
Modelling the Eddystone Lighthouse response to wave loading
}

Trinh, Q

http://hdl.handle.net/10026.1/5228

10.1016/j.engstruct.2016.06.027

Engineering Structures

Elsevier

All content in PEARL is protected by copyright law. Author manuscripts are made available in accordance with publisher policies. Please cite only the published version using the details provided on the item record or document. In the absence of an open licence (e.g. Creative Commons), permissions for further reuse of content should be sought from the publisher or author. 


\section{Modelling the Eddystone Lighthouse response to wave loading}

\section{Abstract}

The Eddystone Lighthouse is an imposing granite structure that has guided mariners through the treacherous waters off the Plymouth coast for almost 150 years. The General Lighthouse Authorities (GLA) of the UK and Ireland, recognising the continuing importance of rock-mounted lighthouses as physical aids for navigation, funded a pilot project, commissioning Plymouth University to monitor the tower. The present study aims to provide more information on the structural behaviour of the Eddystone Lighthouse under the impacts from wave loading, through the utilisation of a 3D finite element model. Data from geophones, an offshore wave buoy and video cameras installed on the tower have been used to calibrate and validate the model; in particular, the wave that caused the maximum displacement during the winter 2013/2014 storms has been considered. The point of application of the wave load is important in the tower's structural response; the lighthouse being particularly vulnerable to larger displacements when the wave acts above its cylindrical base. Finite element analysis suggests that the lighthouse is stable with regard to material failure, and for failure mechanisms of overturning and sliding there are factors of safety of 6.3 and 8.0 respectively. A hypothetical unbroken wave of $17.5 \mathrm{~m}$ height would be required to overturn the lighthouse, and one of height $17 \mathrm{~m}$ would cause cracking at the base, but in such a location these waves would not be possible.

\section{Introduction}

The magnificent granite Eddystone Lighthouse is a structure of incalculable cultural importance. Taking its name from the Eddystone Rocks on which it was built, a gneiss reef some $22.5 \mathrm{~km}$ south south-west of Plymouth in the UK, the current lighthouse is an engineering masterpiece designed by James Nicholas Douglass. The so-called Douglass Tower has withstood the forces of the Atlantic Ocean since 1882, marking the presence of these treacherous rocks. Figure 1 (a) shows the lighthouse in benign conditions alongside the stump of the preceding Smeaton's tower, the upper courses of which now stand on 
Plymouth Hoe. The construction of these rock lighthouses is well-described (see e.g. [1]; [2]; [3]; [4]) but limited observations of structural response have been provided in archive literature. The most notable accounts are by Robert Stevenson on Bell Rock lighthouse ([4]; [5]) and as reported on a number of previous Eddystone lighthouses ([1]; [5]). Whilst fascinating to read, at best they provide a patchy understanding of how wave impacts are related to tower motions.

Despite modern navigation technologies, such as the Global Positioning System, the UK General Lighthouse Authorities (GLAs) are committed to maintain their rock lighthouses as a physical aid for navigation, as satellite systems are by no means failsafe. However, the anticipated increase induced by climate change in sea level, general storminess and in particular individual extreme wave heights could undermine the stability of these structures. In this regard, the GLAs have funded a pilot project commissioning Plymouth University to monitor the Eddystone Lighthouse; four video cameras and two geophone systems have been installed on the tower, in order to better understand its long term stability against impacting waves [5].

This paper presents the structural behaviour of the Eddystone Lighthouse through the utilisation of a Finite Element (FE) model. Other aspects of the project reported elsewhere include anecdotal observations of wave loading and structural response [5], comprehensive details of the wave hydrodynamics and a description of the wave characteristics that influence the tower motions (in preparation). To properly model the behaviour of the tower, historical archive drawings of the tower have been used to accurately represent its complex geometry, while data from the video cameras and geophones were utilised to calibrate the material properties and define the wave load. The event considered is the wave that induced the highest displacement in the tower during the winter storms of 2013/2014; for England and Wales, this was one of the most exceptional periods of winter rainfall in at least 248 years and the stormiest weather for 52 years [6]. 
The steps followed in the realisation of the FE model have been: construction of the geometry, assignment of an adequate mesh and of the material properties, definition of the boundary conditions and of the wave load.

\section{Structure geometry}

The lighthouse consists of two parts: a solid cylindrical base, $13.4 \mathrm{~m}$ in diameter and $6.7 \mathrm{~m}$ high, on top of which is a tapered tower with a maximum and minimum diameter of $10.7 \mathrm{~m}$ and $7.2 \mathrm{~m}$ respectively (Figure 1). The 2171 blocks of granite constituting the structure were laid in less than four years, from 1878 to 1882, under the supervision of Douglass. Each block was dovetailed to the next (Figure 2) and a liquefied mortar of cement Portland was poured to fill the remaining voids in the grooves. The blocks fitted so closely together that it is said the tower, in total tall $41.5 \mathrm{~m}$ and weighing 4743 tonnes, could have been built without the need for mortar [2].

Excluding a water tank built into the solid base section, the interior of the tower comprises nine rooms, with the thickness of the walls varying from $2.6 \mathrm{~m}$ at the bottom to $0.7 \mathrm{~m}$ at the top. Above these comes the lantern room, converted in 1959 to electricity formerly having used Argand burners, then paraffin lamps to provide the warning light. A helideck on top of the lantern was built in 1980, supported on a latticework of steel attached to the top courses of masonry [2].

\section{Monitoring instrumentation and results}

In order to monitor and better understand the structural behaviour of the Eddystone Lighthouse, Plymouth University installed the following instrumentation on the tower:

1. Four remote-controlled, DC-powered video cameras, to record the wave conditions around the structure [5]. They were attached to the helideck structure, and controlled remotely by internet from the Plymouth University campus. Three cameras were downwards-pointing in the directions SW, NNW, ESE, while the remaining camera was angled towards the 'far-field' of the SW direction, to provide information about wave 
transformation across the reef. Video images were captured with a rate of 1 or 5 frames per second depending on whether wave activity was detected over the base of the tower.

2. Two geophone systems (RDL //Vibe) to measure the structural response of the tower in terms of velocity time histories [5]. Displacements and accelerations were then obtained from the velocities through integration or differentiation respectively. The acquisition rate was either $100 \mathrm{~Hz}$ (around $10 \mathrm{~s}$ of acquisition) or $500 \mathrm{~Hz}$ (around $2 \mathrm{~s}$ of acquisition), limited by a maximum number of data points from any event.

In this study, the wave that in winter 2013/2014 caused the largest displacement of the Eddystone Lighthouse is considered; video images (Figure 3) have been used to evaluate the distance between wave breaking and the tower and its resulting impact area, while the geophone displacement signals and amplitude spectra were utilised to calibrate the FE model. To this aim, only the dynamic component of the displacement was considered, obtained from the total geophone signal by eliminating the quasi-static contribution through a high-pass filter with a cut-off frequency of $0.5 \mathrm{~Hz}$; this operation was carried out because the quasi-static load has little influence on the overall response of the structure. The largest displacement at the geophone location (positioned at $26 \mathrm{~m}$ from the top of the cylindrical base) was $0.0745 \mathrm{~mm}$ (see Figure 4); this low value gives an idea of the colossal stature of the tower.

Alongside video images, statistical information of the wave environment was obtained from the E1 data buoy, a Western Channel Observatory buoy operated by Plymouth Marine Laboratory, situated around 15 miles $(24 \mathrm{~km}) \mathrm{SW}$ of the Eddystone reef.

\section{Structural Model}

\subsection{Modelling approach}

Prior to the development of an FE model, the relevant information about the structure must be gathered. This includes, for example, the historical information, the materials and geometry as described by Pena et al. (2010) [7]. Information on the dynamic response of 
the structure can be gained from monitoring or vibration tests with accelerometers. In recent years, the recording of ambient vibration has become the conventional testing method, since no excitation equipment is needed, hence there is minimal interference with the normal use of the structure [8]. The natural frequencies of the structure can then be estimated by analysing the power spectral response obtained from the accelerometer signals [9] (or geophones as used in this study), while the modal shapes could be determined if more accelerometers/geophones are present on the structure; for example, a dominant bending mode is identifiable when all the sensors show the same harmonic [10].

Once all the necessary information has been acquired, the construction and calibration of the FE model can be carried out. There are several proprietary finite element analysis (FEA) software packages that could be used to model a structure, such as SAP2000, DIANA, LUSAS. The LUSAS package [11] has been used here since it was readily available for this pilot project. When modelling slender masonry towers, solid elements are usually implemented for the walls, while solid or shell elements could be used to model the floors [12]. With regard to the calibration of the FE model, it was limited to the definition of a fictitious roof simulating the mass of the helipad structure (since it was not possible to model the fine details) and the assessment of the damping coefficients (see Section 4.3). For the material properties, the adopted values for the granite were based on the literature that described the construction [5]. This was done because the origin of the construction materials was well-known and their mechanical properties are well-defined. Also, there is no evidence of damage along the structure that justifies the variation of the mechanical properties with respect to the nominal values. However, in case more uncertainties are associated with the material properties, more complex numerical techniques could be used to tune them and minimise the difference between the computational and the experimental behaviour ([7]-[10],[12]). In masonry structures, for instance, the distributions of the elastic modulus, $E$, and the density, $\rho$, are usually non-uniform, and the calibration process could require the subdivision of the structure in different zones, each characterised by a different 
value of $E$ and $\rho$; in this case, the calibration is usually implemented with numerical strategies, such as the Inverse Eigen-Sensitivity and the Douglas-Reid (DR) methods ([12]; [8]).

\subsection{Mesh assignment}

In order to minimise the computational time necessary to solve the transient dynamic problem, the decision was made not to model individual dovetailed blocks, but instead to represent the Eddystone Lighthouse as a monolithic structure. Creation of the geometry was achieved by referring to the historic drawings of the tower with a slight modification of the cylindrical base from a height of $6.7 \mathrm{~m}$ to $5.6 \mathrm{~m}$ since the first 2 courses in the Eddystone Lighthouse are incomplete due to uneven bedrock levels and have therefore not been modelled. After this it was necessary to construct an appropriate mesh. The hexahedral element type was selected for this study, since the complex geometry of the tower, comprising window openings and chambers throughits height, can be appropriately modelled with this choice. Moreover, the hexahedral element usually gives better results than the tetrahedral and pentahedral element types [13].

Different mesh refinements, obtained by changing the number of elements and interpolation order (linear or quadratic), were tested and compared, both in quasi-static and dynamic analyses. Then, the mesh giving the best compromise between required running time and precision was selected (Figure 5). This mesh, formed of 1558 hexahedral elements with quadratic interpolation functions, for a total of 9944 nodes (29832 degrees of freedom), was more refined in the zone where the impact wave was likely to act, namely between the $13^{\text {th }}$ and $26^{\text {th }}$ courses; this allowed the application of a more accurate wave load.

As far as the boundary conditions were concerned, the bottom surface of the lighthouse was considered as fully fixed. With reference to the original structure, this would certainly be the most obvious condition since all the blocks of granite in the lowest course were not only cemented and dovetailed to the reef, but also bolted with heavy iron bolts [2]. In today's situation, we can conservatively assume that the connection given by the bolts is no longer 
effective due to a deterioration of the bolts and, therefore, the shear load is transferred only by friction. In this regard, the analyses presented in Section 7 show how the base is always in compression and the friction alone is able to globally resist the critical wave load. These results support the choice of a perfect bond between the base of the tower and the reef.

\subsection{Model calibration through modal analysis}

The Eddystone Lighthouse comprises granite from two different locations: the quarries of De Lank (Cornwall) and Dalbeattie (Scotland) [1]. The Dalbeattie blocks were used to complete the solid portion of the tower, while the De Lank blocks were used for the remaining part of the tower [14]. Their mechanical properties were obtained from Bell (1983) [15] and from the De Lank Quarry Limited (St. Breward, Nr Bodmin, Cornwall) respectively (Table 1). As these values were fixed, the calibration of the model required modelling and tuning of a fictitious roof, simulating the lantern and helipad structure.

Table 1 - Mechanical properties of the De Lank and Dalbeattie granites

\begin{tabular}{|l|r|r|}
\cline { 2 - 3 } \multicolumn{1}{c|}{} & De Lank granite & Dalbeattie granite \\
\hline Young's modulus (E) & $32.3 \mathrm{GPa}$ & $41.1 \mathrm{GPa}$ \\
\hline Density $(\boldsymbol{\rho})$ & $2644 \mathrm{~kg} / \mathrm{m}^{3}$ & $2670 \mathrm{~kg} / \mathrm{m}^{3}$ \\
\hline Compressive strength $\left(\boldsymbol{\sigma}_{\mathrm{c}}\right)$ & $219 \mathrm{MPa}$ & $147.8 \mathrm{MPa}$ \\
\hline
\end{tabular}

From the displacement spectrum obtained from the geophones signal, the fundamental frequency of the lighthouse was determined to be $4.36 \mathrm{~Hz}$. To attain a fundamental frequency similar to the one recorded by the geophones, a fictitious roof with an arbitrary thickness of $1 \mathrm{~m}$ was modelled upon the last course (Figure 5), and its material properties were calibrated. Given that the 'roof structure' presents numerous elements (e.g. the light and its lenses; the lantern including its roof and walkway; the helipad and its support structure; the PV panels and their support structure) there were great uncertainties on the values of the Young's modulus and density to be used. However, since the stiffness of the roof has a small influence on the overall behaviour of the tower, a value of $32.3 \mathrm{GPa}$ was chosen for the Young's modulus, in continuity with the value assigned to the granite on 
which the roof is attached. A mass density of $2300 \mathrm{~kg} / \mathrm{m}^{3}$ for the roof gave an FE fundamental frequency equal to the one obtained from the geophones (i.e. $4.36 \mathrm{~Hz}$ ). Figure $5 \mathrm{c}$ shows the material properties distribution in the FE model, while Table 2 presents the first 10 modes of vibration obtained using LUSAS.

Table 2 - First 10 natural modes of vibration obtained with the LUSAS model modified with the fictitious roof

\begin{tabular}{|c|c|c|c|}
\hline Mode & Natural Frequency, $\mathbf{f}(\mathbf{H z})$ & Period, T (s) & Mode shape description \\
\hline 1 & 4.36 & 0.229 & First bending Y-axis \\
\hline 2 & 4.39 & 0.228 & First bending X-axis \\
\hline 3 & 15.17 & 0.066 & Second bending X-axis \\
\hline 4 & 15.30 & 0.065 & Second bending Y-axis \\
\hline 5 & 20.73 & 0.048 & First torsional \\
\hline 6 & 29.18 & 0.034 & First axial \\
\hline 7 & 30.66 & 0.033 & Third bending X-axis \\
\hline 8 & 30.86 & 0.032 & Third bending Y-axis \\
\hline 9 & 43.27 & 0.023 & Second torsional \\
\hline 10 & 48.64 & 0.021 & Fourth bending Y-axis \\
\hline
\end{tabular}

To analyse the response of the lighthouse to the impact of waves, the damping characteristics of the model had to be first determined. If the damping can be assumed to be proportional (Rayleigh damping), the damping matrix can be expressed as a linear combination of the mass matrix and the stiffness matrix [16]:

$$
[C]=a_{0}[M]+a_{1}[K]
$$

The damping ratio for the $\mathrm{n}^{\text {th }}$ mode is:

$$
\zeta_{n}=\frac{a_{0}}{2} \frac{1}{\omega_{n}}+\frac{a_{1}}{2} \omega_{n}
$$

where the coefficients $a_{0}$ and $a_{1}$, the mass and stiffness Rayleigh damping constants, can be determined from specific damping ratios $\zeta_{i}$ and $\zeta_{j}$ for the $\mathrm{i}^{\text {th }}$ and $\mathrm{j}^{\text {th }}$ modes respectively.

Expressing Equation (2) in matrix form for these two modes gives:

$$
\frac{1}{2}\left[\begin{array}{ll}
1 / \omega_{i} & \omega_{i} \\
1 / \omega_{j} & \omega_{j}
\end{array}\right]\left(\begin{array}{l}
a_{0} \\
a_{1}
\end{array}\right)=\left(\begin{array}{l}
\zeta_{0} \\
\zeta_{1}
\end{array}\right)
$$


If both modes are assumed to have the same damping ratio $\zeta$, which is reasonable based on experimental data [16], then:

$$
\begin{aligned}
& a_{0}=\zeta \frac{2 \omega_{i} \omega_{j}}{\omega_{i}+\omega_{j}} \\
& a_{1}=\zeta \frac{2}{\omega_{i}+\omega_{j}}
\end{aligned}
$$

and the damping matrix can be determined using Equation (1).

The modes $\mathrm{i}$ and $\mathrm{j}$, with specified damping ratios, should be chosen to ensure reasonable values for the damping ratios in all the modes contributing significantly to the response. In fact, the definition of $\zeta_{n}$ given by Equation (2) ensures that the damping ratio of all of the modes included between modes $\mathrm{i}$ and $\mathrm{j}$ will be slightly smaller than the selected value $\zeta$. Instead, the damping ratio of higher modes will increase monotonically with frequencies and the corresponding modal responses will be essentially eliminated from the global response of the structure.

In the absence of experimental tests, the value of the damping ratio $\zeta$ can be estimated considering the decay of the geophone displacement signal (Figure 4). This signal represents only the dynamic component, obtained from the total one by eliminating the static contribution. Considering the two adjacent peaks reported in Figure 4, the damping ratio can be calculated with Equation (6) [16]:

$$
\zeta=\frac{1}{\sqrt{1+\left(\frac{2 \pi}{\ln \left(x_{0} / x_{1}\right)}\right)^{2}}}
$$

With values of $x_{0}=0.0215 \mathrm{~mm}$ and $x_{1}=0.0183 \mathrm{~mm}, \zeta$ is equal to $2.56 \%$.

In our study, the modes that contributed significantly to the response were deemed to be modes 1-6, because the lowest peak that could be seen in the geophones' amplitude 
spectra corresponded to a frequency of approximately $28.5 \mathrm{~Hz}$; this value is close to the sixth natural frequency of $29.18 \mathrm{~Hz}$ (axial mode) found from the FE analysis.

Using Equations (4) and (5), with $\omega_{i}=\omega_{1}=(2 \pi) / T_{1}=27.4 \mathrm{rad} / \mathrm{s}$ and $\omega_{j}=\omega_{6}=(2 \pi) / T_{6}=$ $183.32 \mathrm{rad} / \mathrm{s}$, the Rayleigh damping constants have then been estimated to be equal to $\mathrm{a}_{0}=$ $1.22 \mathrm{rad} / \mathrm{s}$ and $\mathrm{a}_{1}=2.44 \times 10^{-4} \mathrm{~s} / \mathrm{rad}$.

\section{Wave load}

\subsection{Wave loading descriptions}

A literature review for the present study has revealed a paucity of rock lighthouse wave loading research, though numerous laboratory studies have been conducted on cylindrical structures situated in deep water and intermediate depth, such as wind turbines and oil platforms. The presence of reefs around lighthouses causes incoming waves to become more nonlinear and ultimately break due to the shallow water. Also, unlike wind turbines and oil platforms, lighthouses are generally constructed above mean water. Furthermore, their geometries are almost exclusively tapered, like that of a tree trunk. However, with no other guidance available, wave loading on surface-piercing cylinders had to serve as a proxy. The total wave load acting on a cylinder is usually expressed as the sum of a dynamic component, which acts for a very short time and can be seen as an impact load, and a quasi-static component, which varies in time in accordance with the water surface elevation associated with the wave cycle [17]. Given the complexity of the wave loading phenomena several contrasting formulations for wave loading on cylinders have been published. For example, Goda et al. (1966) [18] and Wienke \& Oumeraci (2005) [17] provide different expressions for the dynamic component, while the quasi-static component could be estimated using the methods of Morison et al. (1950) [19] or Irschik et al. (2004) [20]. In the present study, the dynamic component of the load was estimated using the theory of Wienke \& Oumeraci (2005) [17] since it forms the basis of ISO 21650 'Actions from wave and currents on coastal structures' [21]. The quasi-static component was neglected, since 
the maximum displacement was reached approximately $0.1 \mathrm{~s}$ after the wave impact and hence was not influenced by the quasi-static load.

\subsection{Application of wave load}

The load was based on the best estimations of the wave that yielded the largest displacement as measured by the geophones. It was applied in the SW direction, corresponding to the negative $y$-axis of Figure 5. The time history of wave is represented mathematically by Equations (7) and (8), as proposed by Wienke \& Oumeraci (2005) [17]:

$$
\begin{gathered}
\mathrm{F}(\mathrm{t})=\lambda \eta_{\mathrm{b}} \cdot \rho_{w} \mathrm{w} \cdot \mathrm{R} \cdot \mathrm{V}^{2}\left(2 \pi-2 \sqrt{\frac{\mathrm{V}}{\mathrm{R}} \mathrm{t}} \cdot \operatorname{atanh} \sqrt{1-\frac{1}{4} \frac{\mathrm{V}}{\mathrm{R}} \mathrm{t}}\right) \\
0 \leq \mathrm{t} \leq \frac{1}{8} \frac{\mathrm{R}}{\mathrm{V}} \\
\mathrm{F}(\mathrm{t})=\lambda \eta_{\mathrm{b}} \cdot \rho_{w} \cdot \mathrm{R} \cdot \mathrm{V}^{2}\left(\pi \sqrt{\frac{1}{6} \frac{\mathrm{R}}{\mathrm{V} \mathrm{t}^{\prime}}}-\sqrt[4]{\frac{8}{3} \frac{\mathrm{V}}{\mathrm{R}} \mathrm{t}^{\prime}} \cdot \operatorname{atanh} \sqrt{1-\frac{\mathrm{V}}{\mathrm{R}} \mathrm{t}^{\prime} \sqrt{6 \frac{\mathrm{V}}{\mathrm{R}} \mathrm{t}^{\prime}}}\right) \\
\frac{3}{32} \frac{\mathrm{R}}{\mathrm{V}} \leq \mathrm{t}^{\prime} \leq \frac{12}{32} \frac{\mathrm{R}}{\mathrm{V}} \quad \mathrm{t}^{\prime}=\mathrm{t}-\frac{1}{32} \frac{\mathrm{R}}{\mathrm{V}}
\end{gathered}
$$

where $\eta_{b}$ is the crest elevation with respect to the still water level, $\lambda$ is the curling factor equal to 0.46 [9], $\rho_{w}$ is the water mass density, $\mathrm{R}$ is the average radius of the lighthouse in the impact zone and $\mathrm{V}$ is the water velocity.

For a typical plunging wave, $\mathrm{V}$ is assumed equal to the wave celerity $(\mathrm{C})$, and, recalling the wave breaking limit $\left(H_{b} / h_{b} \approx 1\right.$, where $H_{b}$ and $h_{b}$ are the wave height and water depth at breaking point (subscript b), respectively), Equation (9) is obtained:

$$
V=C_{b}=\sqrt{g h_{b}} \approx \sqrt{g H_{b}}
$$

The wave height at the breaking point $\mathrm{H}_{\mathrm{b}}$ is estimated using the method of Goda (2000) [22] as follows. From the E1 buoy situated offshore it is known that the significant wave height in the offshore area is $H_{s, 0}=3.3 \mathrm{~m}$ and that the wave peak period $T_{p}$ is equal to $16.7 \mathrm{~s}$. From 
this information it is possible to calculate the wave steepness $S_{0}$ through Equation (10), in which $L$ is the wavelength and $g$ the gravitational acceleration:

$$
S_{0}=\frac{H_{S, 0}}{L}=\frac{H_{S, 0}}{\frac{g T_{p}^{2}}{2 \pi}}=0.008
$$

Fixing the sea slope to $1 / 10$ (realistic for that location as deduced from a bathymetric survey) and considering $S_{0} \cong 0.01$, Goda's wave height ratio to relative water depth graph (Goda, 2000 [22]) (Figure 6) can be used to determine the maximum wave height at breaking point $H_{b, \max }$. From Figure 6, it can be estimated that $H_{b, \max }=2.45 \times H_{s, 0}=8 \mathrm{~m}$.

Table 3 lists the values used in Equations (7) and (8) to calculate the impact load curve for the Eddystone Lighthouse.

Table 3 - Values used to calculate the impact time history according to Wienke \& Oumeraci (2005)[17]

\begin{tabular}{|cccc|}
\hline$\lambda$ & 0.46 & {$[-]$} & Curling factor \\
$\eta_{\mathrm{b}}=0.78 \mathrm{H}_{\mathrm{b}, \max }$ & 6.24 & {$[\mathrm{~m}]$} & Crest elevation \\
$\rho$ & 1025 & {$\left[\mathrm{~kg} / \mathrm{m}^{3}\right]$} & Water density \\
$\mathrm{R}$ & 4.83 & {$[\mathrm{~m}]$} & Average radius \\
$V$ & 8.86 & {$[\mathrm{~m} / \mathrm{s}]$} & Water velocity \\
\hline
\end{tabular}

Then according to Equations (7) and (8), the total duration of the impact is $T=\frac{12}{32} \frac{R}{V}=0.22 \mathrm{~s}$, whereas the maximum impact force, for $\mathrm{t}=0$, is equal to $7007 \mathrm{kN}$. The resulting normalised load curve is shown in Figure 7.

However, this wave load corresponds to the most critical situation, in which the wave breaks against the lighthouse [17]. This is not the case for the Eddystone Lighthouse where video images show that for severe loads the wave breaking is roughly estimated to occur at a distance of at least $25 \mathrm{~m}$ from the tower (Figure 8). Wienke (2001) [23] provides experimental results that correlate the load intensity with the breaking distance of the wave from a cylinder, for a particular maximum wave height of $1.55 \mathrm{~m}$ (Figure 9). The horizontal axis can be made dimensionless by dividing breaking distance, $\mathrm{x}$, by $\mathrm{H}_{\max }=1.55 \mathrm{~m}$. Knowing that the dimensionless breaking distance, $\mathrm{d}$, for the Eddystone Lighthouse is equal 
to $d=x / H_{b, \max }=25 / 8=3.13$ (-3.13 in Figure 9 due to the axis orientation), a reduction factor for the load of 2.4/1.5=1.6, according to Figure 9, could be assumed. This allows a more realistic loading case to be applied, with a maximum impact force equal to $4379 \mathrm{kN}=$ $7007 / 1.6 \mathrm{kN}$.

The impact zone has been estimated from video camera images, while the assumed load spatial distributions follow those proposed by Tanimoto et al. (1986) [24] (triangular vertical distribution) and Wienke \& Oumeraci (2005) [17] (azimuthal horizontal distribution), shown in Figure 10. In Figure 10, $\mathrm{f}$ is the impact line force $(\mathrm{kN} / \mathrm{m})$, representing the distribution of the impact force $\mathrm{F}(\mathrm{kN})$ along the height of the impact area.

Dynamic analysis has been carried out through a time step analysis, with an implicit integration time method, considering a lumped mass matrix and the damping characteristics estimated in Section 4.3. Given the impulsivity of the impact (the impact total duration is $T=$ $0.22 \mathrm{~s}$ ) and the fact that the peak occurs in the first $0.1 \mathrm{~s}$, a small time step was utilised (i.e. $\Delta \mathrm{t}=0.002 \mathrm{~s}$ ) to obtain an accurate solution.

The displacement history obtained from the FE model for the point corresponding to the position of the geophone is shown in Figure 11, where it is compared with the real displacements, obtained by integrating the velocities captured by the geophone. The comparison shows relatively poor agreement in the first $0.15 \mathrm{~s}$ with an FE peak amplitude in the direction of the wave impact of $0.0998 \mathrm{~mm}, 30 \%$ higher than the value derived from the geophone data $(0.0745 \mathrm{~mm})$. N.B. The wave impact is directed toward the negative $y$-axis. However, beyond $0.15 \mathrm{~s}$ the FE signal matches the geophone signal well in terms of amplitude and frequency with only a modest phase shift. This gives confidence that the construction and calibration of the FE model have been performed to an acceptable degree and that the model is able to reasonably model the dynamic behaviour of the actual structure. 
Figure 12 shows the corresponding displacement amplitude spectra obtained from the FE signal and the geophone. The FE model is able to capture the natural frequencies of $4 \mathrm{~Hz}$, $15 \mathrm{~Hz}$ and $28 \mathrm{~Hz}$, even though it is slightly more flexible than the actual structure, since the frequencies of the numerical analysis are lower than those obtained from the geophone. A significant difference between the two spectra is that the $8 \mathrm{~Hz}$ frequency is not evident from the FE analysis. There are a number of possible reasons for the absence of this vibration mode. The most likely cause is the simplistic representation of the combined helideck structure and lantern room at the top of the structure. Detailed drawings exist for these elements but their representation in this pilot study was deemed unnecessary. Another potential factor is that the reef on which the lighthouse stands was not included in the model. Certainly wave impacts on the reef will influence the lighthouse vibrations: the earlier Smeaton lighthouse was removed from the Eddystone reef because of a 'dangerous abscess' in the rock [1] with associated vibrations of the tower. The effect of the absence of mortar and the connections between the base and the reef are likely to be limited to slight changes in modal frequencies.

As a further remark, we acknowledge that the effects of temperature were not considered in the evaluation of the natural frequencies from the geophone data, since this parameter was not monitored. The natural frequencies were obtained by analysing the geophone data referred to different storm events, all of them taking place in the winter season, and then averaged without considering the temperature effect. According to the work carried out by Saisi et al. [25], the natural frequencies of a masonry structure slightly increase with temperature. Variations between 5 and $11 \%$ were evidenced for temperatures varying from 2 to $45^{\circ} \mathrm{C}$, due to the closure of superficial cracks, minor masonry discontinuities or mortar gaps induced by the thermal expansion of materials. However, compared to a masonry structure the present tower is more monolithic and less sensitive to the behaviour of the mortar joints due to the presence of the dovetail connections. Therefore, the effects of the temperature should be less relevant. 


\section{Wave load parametric study}

The dynamic wave load defined in Section 5 was next applied to impact areas shifted below and above the location previously considered, but with the same wave load characteristics and the same vertical and azimuthal distributions. This was carried out to better understand how the structural response of the lighthouse is influenced by the height of the impact area.

Figure 13 shows how the maximum displacement grows with the height of the upper limit of the impact area, the height being defined relative to the bottom of the cylindrical base. When the impact load acts completely (or partly) on the base, the maximum displacement grows linearly with impact height. However a much steeper linear trend is evident beyond an elevation of $8 \mathrm{~m}$, where the impact load acts completely above the base; in this case, with an increase in the impact area height of $0.5334 \mathrm{~m}$ (equivalent to the height of one course of blocks) the average increment of the maximum displacement is $16 \%$. This increased displacement is due to the fact that the base has a larger radius and can be considered to be a massive structure, which absorbs most of the impact, while the upper part is more slender and comprises openings (windows and a door) and cavities (rooms), making the tower more flexible.

This investigation shows that the structural response is highly influenced by the height at which the wave acts, which in turn depends on the tide level, on the breaking distance and on the maximum wave height $\mathrm{H}_{\mathrm{b}, \max }$ at the breaking point.

\section{Stability analysis}

The stability of the lighthouse was analysed with respect to three possible failure mechanisms: material failure, overturning and sliding. The material failure was evaluated assuming that the Eddystone Lighthouse is a monolithic granite structure, while the failures due to overturning and sliding were considered with the conservative hypothesis that the original iron rods securing the base to the reef were no longer effective. 


\subsection{Material failure}

Material failure occurs when the stress state at a point of the structure, as defined by the principal tensions, is tangential to the assumed failure domain. To obtain the stress distribution in the lighthouse, the stress due to self-weight is added to that caused by the wave impact.

The vertical normal stress distribution due to self-weight only is shown in Figure 14; the materials remain in the elastic field, since the level of stress is everywhere smaller than the intrinsic strength. The total weight obtained from LUSAS is $51340 \mathrm{kN}$, equal to a mass of 5233 tonnes. Removing the fictitious roof this gives a weight of 5140 tonnes, only $8 \%$ higher than the value of 4743 tonnes obtained from Nicholson (1983) [2] for the granite parts of the structure.

Applying the wave, the point subjected to the maximum vertical stress was at the base, on the side of the impact area (point $A$ in Figure 15), and the maximum stresses induced by the wave occur at $0.012 \mathrm{~s}$ from the beginning of the impact. Whilst it should be borne in mind that the agreement in the FE and geophone time signals was fairly poor before $0.15 \mathrm{~s}$, the LUSAS model over-predicts the maximum displacement and hence any findings can be regarded as conservative. Figure 15 shows the combined vertical stress distribution in the lighthouse at $0.012 \mathrm{~s}$, while Figure 16 indicates how the application of the wave changes the vertical stress along the bottom of the base, at $0.012 \mathrm{~s}$. It can be seen that all of the base remains compressed. The obtained stress distribution with concentrations at the ends is due to the fixed constraints assumed for the bottom surface of the tower. This distribution is in accordance with the analytical solution provided by Tarn et al. (2009) [26] for the case of a circular elastic cylinder under its own weight; their study showed that the 'end effect' is more pronounced when the bottom plane is perfectly bonded respect the case of smooth contact with a rigid base. 
The Mohr-Coulomb failure criterion was considered in order to evaluate the material failure, since it is suitable for describing the failure of materials in which the compressive strength far exceeds the tensile strength [27]. In the Mohr diagram this criteria is represented by Equation (11):

$$
\tau=\tau_{c}+\sigma \tan \varnothing
$$

where $\tau_{c}$ is the shear strength in the absence of vertical compression, $\varnothing\left(^{\circ}\right)$ is the angle of internal friction and $\sigma$ is the vertical compression. For granites, $\tan \emptyset$ is assumed to be 0.7 , with $\varnothing=35^{\circ}([28]$; [29]). The base of the lighthouse comprises blocks of the Dalbeattie granite with a compressive strength of $\sigma_{\mathrm{c}}=147.8 \mathrm{MPa}$. The tensile strength can be assumed 40 times smaller than the compressive strength [30], therefore a value of $\sigma_{t}=3.7$ MPa was considered. The shear strength, in the absence of compression, can be fixed at $\tau_{c}$ $=31 \mathrm{MPa}$ [29]. Considering these values, the failure domain was obtained by plotting Equation (11) with the two vertical cut-offs corresponding to the tensile and compressive strengths (Figure 17). In Figure 17, the stress state in point $A$ at $0.012 \mathrm{~s}$ is also plotted $\left(\sigma_{1}=\right.$ $\left.-281.69 \mathrm{kPa}, \sigma_{2}=-38.08 \mathrm{kPa}, \tau_{\max }=121.8 \mathrm{kPa}\right)$.

It can be seen that the stress state of the point subjected to the maximum (with sign) vertical stress (point $A$ at $0.012 \mathrm{~s}$ ) is well inside the failure domain. The structure remains in the elastic region, and the stability against material failure for the monolithic model under this particular applied load is guaranteed.

\subsection{Overturning}

Failure due to overturning occurs if the destabilising moment due to the wave impact is higher than the stabilising moment provided by the self-weight. The moments were calculated around the extreme point at the base, on the opposite side with respect the impact.

The horizontal resulting force due to the wave impact, $R_{\text {wave }}$, is equal to the force previously calculated using the approach of Wienke \& Oumeraci (2005) [17] i.e. $F_{W \& O, \text { reduced }}=4379 \mathrm{kN}$, 
multiplied by an amplification factor taking into account the fact that the load is applied dynamically [31]. The static equivalent wave force can be assumed to be equal to the maximum reaction at the base of the lighthouse when the impact load curve is applied. From the FE simulation, a value of $R_{\text {wave }}=5674 \mathrm{kN}$ was found, therefore giving a dynamic amplification factor of $5674 / 4379=1.3$. The resulting force due to the self-weight, $R_{\text {weight }}$, was obtained from the FE model and is equal to $51340 \mathrm{kN}$.

The moment arm of $R_{\text {wave }}$ is equal to the height of the barycenter of the impact area with respect to the base of the lighthouse, i.e. $7.45 \mathrm{~m}$, whereas the moment arm of $R_{\text {weight }}$ is half the diameter of the base, i.e. $6.71 \mathrm{~m}$. It follows that the destabilizing moment is $M_{\text {destab }}=42.3$ $\times 10^{3} \mathrm{kNm}$ whereas the stabilizing one is $M_{\text {stab }}=344.5 \times 10^{3} \mathrm{kNm}$. The stability of the lighthouse against overturning under these conditions is therefore guaranteed $\left(M_{\text {destab }}<\right.$ $\left.M_{\text {stab }}\right)$, with a safety factor of $M_{\text {stab }} / M_{\text {destab }}=8$.

\subsection{Sliding}

Sliding failure occurs when the horizontal force induced by the wave is higher than the frictional force present at the interface between the base of the lighthouse and the reef. The frictional resistant force is calculated as $R_{\text {friction }}=\mu R_{N}$, where $\mu$ is the friction coefficient and $R_{N}$ the total normal force acting on the potential sliding surface. The friction coefficient $\mu$ was assumed to be equal to 0.7 (since the reef is composed of gneiss with similar properties to granites), while the normal force was equivalent to the resultant force due to self-weight, i.e. $R_{N}=R_{\text {weight }}=51340 \mathrm{kN}$.

It follows that the frictional resistance force is $R_{\text {friction }}=35938 \mathrm{kN}$, while the horizontal force induced by the wave is $R_{\text {wave }}=5674 \mathrm{kN}$, as previously calculated. The stability of the lighthouse against sliding under these conditions is therefore guaranteed ( $R_{\text {wave }}<R_{\text {friction }}$ ), with a safety factor of $R_{\text {friction }} / R_{\text {wave }}=6.33$. 


\subsection{Critical waves}

Considering the previous analyses, two critical waves could be estimated for the lighthouse: the one which produces cracking (i.e. tensile forces at one extremity of the base of the lighthouse) and the one that destabilizes the lighthouse (for overturning or sliding).

The cracking limit does not determine the opening of the joints between the granite blocks since they are linked together with dovetail connections. However, it may be critical for the joint between the tower base and the reef, especially in the hypothesis of full degradation of the iron bolts. The opening of this joint would permit the infiltration of the water, with a consequent acceleration of the material deterioration. The wave that induces cracking has been estimated assuming a linear relationship between impact wave heights and induced vertical stresses (see Figure 18, which shows the vertical stresses in point $A$ ); this assumption is reasonable, given that also for induced displacements a linear trend was found (Figure 13). From Figure 18, it can be deduced that the critical wave that induces tensile stresses in point $A$ has a height of approximately $17 \mathrm{~m}$.

The second, and more severe critical wave, namely the one that undermines the stability of the Eddystone Lighthouse, has been estimated using the load distributions of Wienke \& Oumeraci (2005) [17], assuming the same load reduction factor estimated in Section 5.2 (i.e. 1.6). Figure 19 shows how the safety factors for overturning and sliding decrease with increasing $\mathrm{H}_{\mathrm{b} \text {,max }}$. The safety factor for overturning drops faster than the one of sliding, since, with each increase in wave height, both the wave load and the moment arm increase. Overturning failure occurs for a wave height at the breaking point of $17.5 \mathrm{~m}$, corresponding to an impact force of $21141 \mathrm{kN}$ and a moment arm of $16 \mathrm{~m}$.

However, it must be remembered that the load reduction factor used (i.e. 1.6) has been estimated for a particular wave height of $8 \mathrm{~m}$ (see Section 5.2). Higher waves would break further from the lighthouse (due to depth-limited breaking as the water depth decreases dramatically around the tower) and higher load reduction factors (function of the wave height) should therefore be used. Hence, the results obtained are conservative. 


\section{Conclusions and Further Work}

The aim of the study was to investigate the structural response of the Eddystone Lighthouse under wave loading, through the development of a 3D FE model. The geometry was defined from historic drawings of the tower, while the calibration required the modelling and tuning of a fictitious roof, simulating the lantern and helipad structure. The wave that caused the largest displacements in the tower in winter 2013/2014 was then applied, allowing the verification of the correct construction and calibration of the FE model. It was found that both the displacement signal and the amplitude spectra obtained from the FE model were generally similar to the ones extracted from the geophones.

On the basis of this agreement, the model has been used to evaluate the stability of the lighthouse. Considering the self-weight and the most severe wave of winter 2013/2014 for the loads, the tower remained comfortably safe against the three failure mechanisms analysed - material failure, overturning and sliding. A parametric study was also conducted, and the results demonstrated that the structural response of the lighthouse is highly influenced by the height at which the impact occurs. This in turn depends on the tide level, on the wave breaking distance and on the maximum wave height. Finally, it was possible to estimate that a wave of $17 \mathrm{~m}$ would induce cracking at the base of the lighthouse, while failure of the tower would occur for overturning with a wave of $17.5 \mathrm{~m}$. However, these results, obtained with a load reduction factor of 1.6 , are conservative: since the maximum water depth at the toe of the tower is $6.67 \mathrm{~m}$ (as deduced from a bathymetric survey) high waves break far from the structure, and higher load reduction factors (function of the wave height) should be used.

Whilst the close similarity between the displacement signals obtained with the FE model and the geophones gives confidence in the model, as well as the correct definition of the impact wave, several improvements could be made: a more refined mesh, a more realistic distribution of the material properties, a more accurate modelling of the lantern and helipad structures, and a more precise definition of the boundary conditions and wave loads. Among 
these aspects, the most critical is represented by the wave load definition; the theory of Wienke \& Oumeraci (2005) [17] was implemented in this study, though it was developed for cylinders and for waves breaking right in proximity of the structure. The pilot study has led to a much wider project, STORMLAMP, funded by the UK Engineering and Physical Sciences Research Council. This project will assess a number of rock lighthouses by combined field analysis, structural and physical modelling. The field analysis will use forced and ambient vibration testing, developing long-term monitoring instrumentation for the worst-affected lighthouse. The structural modelling will use field, hydrodynamic laboratory and computational fluid dynamics data to provide better estimations of wave loading and to validate sophisticated FE models. This approach will lead to structural health monitoring methods for rock lighthouses worldwide and to other masonry structures under severe wave loading.

\section{Acknowledgements}

The authors would like to acknowledge the support of the General Lighthouse Authorities, particularly Martin Bransby and Ron Blakeley (ex-Trinity House) and their lighthouse engineers who assisted with deployments on station; Peter Ganderton and Tony Tapp of Plymouth University who designed much of the installed equipment; the School of Marine Science and Engineering at Plymouth University who funded Davide Banfi's studentship. We also acknowledge the helpful comments of the anonymous reviewers.

[1] Majdalany, F. (1959). Red rocks of Eddystone. London: White Lion Publishers Ltd.

[2] Nicholson, C. (1983). Rock Lighthouses of Britain. Cambridge: Patrick Stephens.

[3] Bathurst, B. (2005). The Lighthouse Stevensons. Harper Perennial, London, UK.

[4] Stevenson, R. (1824). An Account of the Bell Rock Light-House Including the Erection and Peculiar Structure of that Edifice. Archibald Constable \& Co, Edinburgh, UK.

[5] Raby, A., Bullock, G.N., Banfi, D., Rafiq, Y. Cali, F. (2015). Wave loading on rock lighthouses. Maritime Engineering http://dx.doi.org/10.1680/jmaen.15.00002

[6] Slingo, J. (2014). The Recent Storms and Floods in the UK. Met Office and Centre for Ecology \& Hydrology.

[7] Pena, F., Lourenco, P., Mendes, N., \& Oliveira, D. (2010). Numerical models for the seismic assessment of an old masonry tower. Engineering Structures, vol 32, 1466-1478. 
[8] Foti, D., Diaferio, M., Giannoccaro, N., \& Mongelli, M. (2012). Ambient vibration testing, dynamic identification and model updating of a historic tower. NDT\&E International, vol 47, 88-95.

[9] Ivorra, S., \& Pallares, F. (2006). Dynamic investigations on a masonry bell tower. Engineering structures, vol 28, 660-667.

[10] Ivorra, S., Pallares, F., \& Adam, J. (2009). Dynamic behaviour of a modern bell tower A case study. Engineering Structures, vol 31, 1085-1092.

[11] LUSAS (2016). LUSAS Finite Element Analysis. Online at: http://www.lusas.com/.

[12] Gentile, C., \& Saisi, A. (2007). Ambient vibration testing of historic masonry towers for structural identification and damage assessment. Construction and Building Materials, vol 21, 1311-1321.

[13] LUSAS. (2013). A Brief Guide to Meshing. Retrieved from www.2.lusas.com:

http://www.2.lusas.com/protected/documentation/1025_Brief\%20Guide\%20to\%20Meshing.p df.

[14] Douglass, W. (1883). The New Eddystone Lighthouse. London: Institution of Civil Engineers, PRO MT 10/495.

[15] Bell, F. (1983). Fundamentals of Engineering Geology. Frome and London: Butterworth \& Co. (Publishers) Ltd.

[16] Chopra, A. (1995). Dynamics of Structures. Theory and Applications of Earthquake Engineering. Englewood Cliffs, New Jersey: Prentice Hall.

[17] Wienke, J., \& Oumeraci, H. (2005). Breaking wave impact force on a vertical and inclined slender pile - theoretical and large-scale model investigations. Coastal Engineering $52,435-462$.

[18] Goda, Y., Haranaka, S., \& Kitahata, M. (1966). Study on impulsive breaking wave forces on piles. Report Port and Harbour Technical Research Institute 6 (5), 1 - 30.

[19] Morison, J., O'Brien, M., Johnson, J., \& Schaaf, S. (1950). The forces exerted by surface waves on piles. Journal of Petroleum Technology, Petroleum Transactions, AIME 189, $149-154$.

[20] Irschik , K., Sparboom, U., \& Oumeraci, H. (2004). Breaking wave loads on a slender pile in shallow water. Proc. 29th Int. Conf. Coastal Eng. Lisbon: ASCE.

[21] ISO (2007) ISO 21650:2007: Actions from waves and currents on coastal structures. International Organization for Standardization, Geneva, Switzerland.

[22] Goda, Y. (2000). Random seas and design of maritime structures. Yokohama: World Scientific.

[23] Wienke, J. (2001). Druckschlagbelastung auf schlanke zylindrische Bauwerke, PhDThesis. TU Braunschweig, Leichtweiss Institute.

[24] Tanimoto, K., Takahashi, S., Kaneko, T., \& Shiota, K. (1986). Impulsive breaking wave forces on an inclined pile exerted by random waves. Coastal Engineering, 2288-2302.

[25] Saisi A., Gentile C., Guidobaldi M. (2015). Post-earthquake continuous dynamic monitoring of the Gabbia Tower in Mantua, Italy. Construction and Building Materials (81), 110-112.

[26] Tarn, J., Tseng, W., \& Chang, H. (2009). A circular elastic cylinder under its own weight. International Journal of Solids and Structures (46), 2886-2896.

[27] Carpinteri, A. (1997). Structural Mechanics. A Unified Approach. London: E \& FN Spon. 
[28] Wyllie, D., \& Mah, C. (2004). Rock slope engineering - Civil and mining. Bury St Edmunds, Suffolk: St Edmundsbury Press.

[29] Schellart, W. (2000). Shear test results for cohesion and friction coefficients for different granular materials: scaling implications for their usage in analogue modelling.

Tectonophysics 324, 1-16.

[30] EN 12372. (2007). Natural stone test methods. Determination of flexural strength under concentrated load. BSI.

[31] Clough, R., \& Penzien, J. (1993). Dynamics of structures. McGraw-Hill Education.

\section{Figure captions}
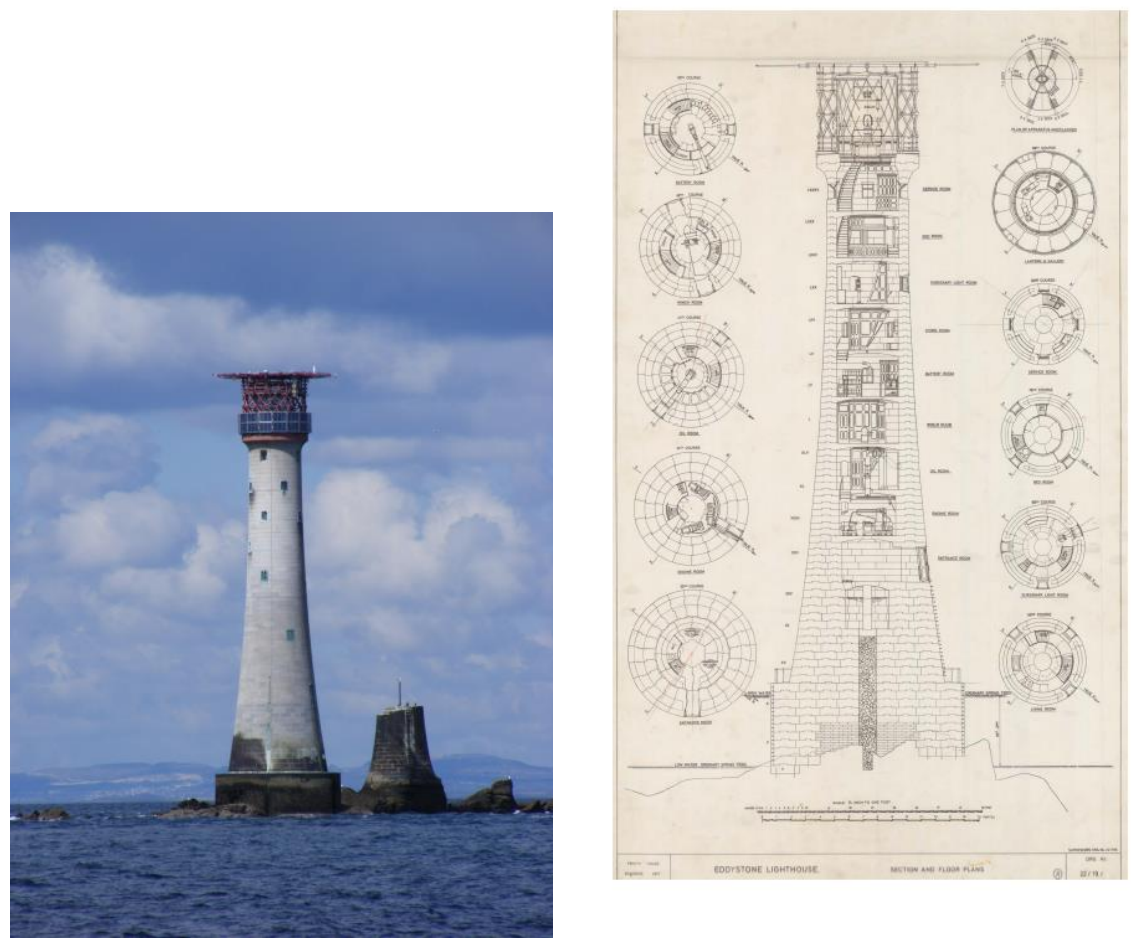

Figure 1 - Douglass Tower, the current Eddystone Lighthouse: (a) photograph alongside stump of previous Smeaton's Lighthouse (Reproduced with kind permission of Helen Nance); (b) sections and floor plans (Reproduced with kind permission of Trinity House). 


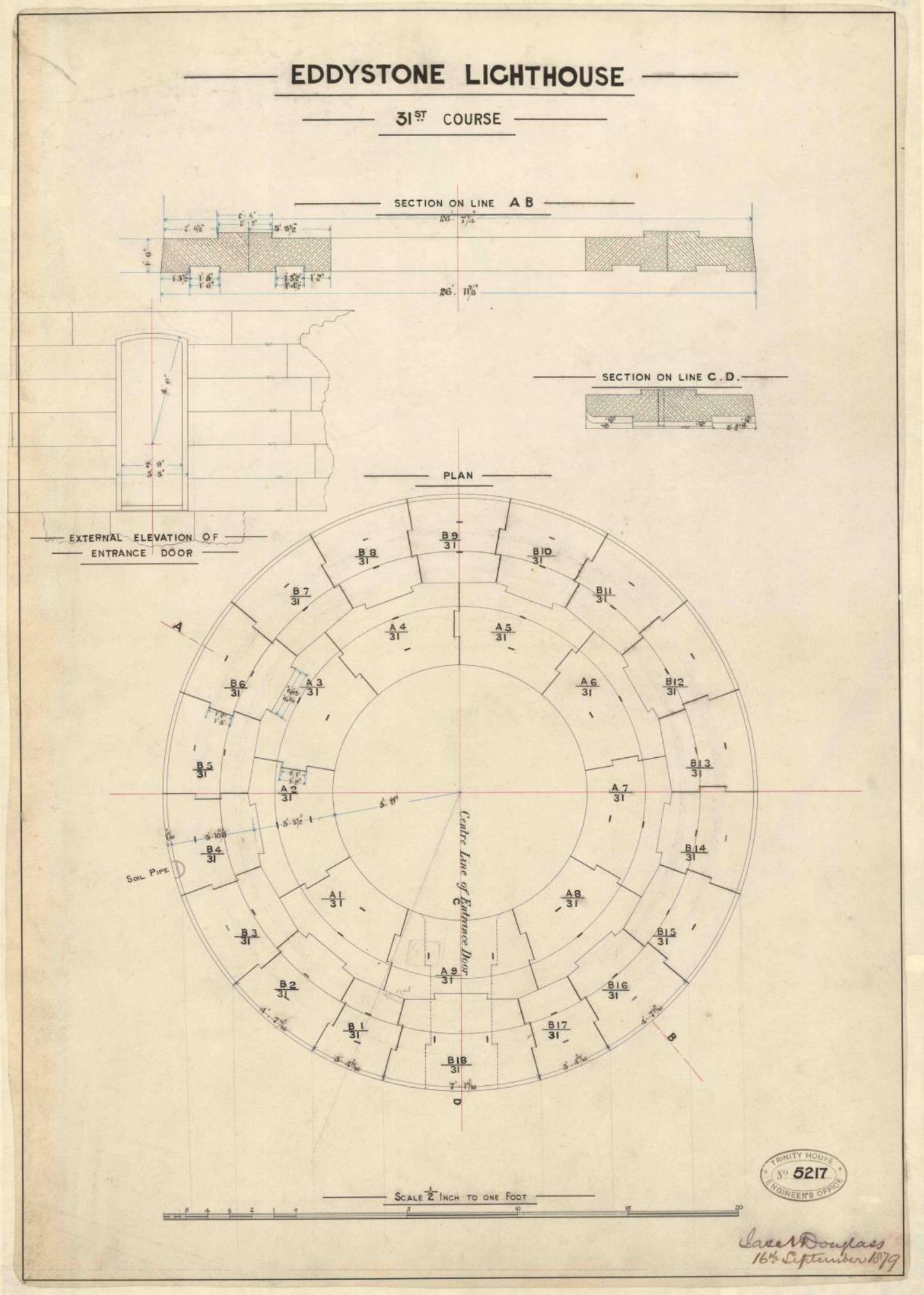

Figure 2 - Archive drawing signed by Douglass, showing plans and sections through the top of the entrance level of the Eddystone Lighthouse. Note the horizontal and vertical dovetail joints (Reproduced by kind permission of Trinity House). 


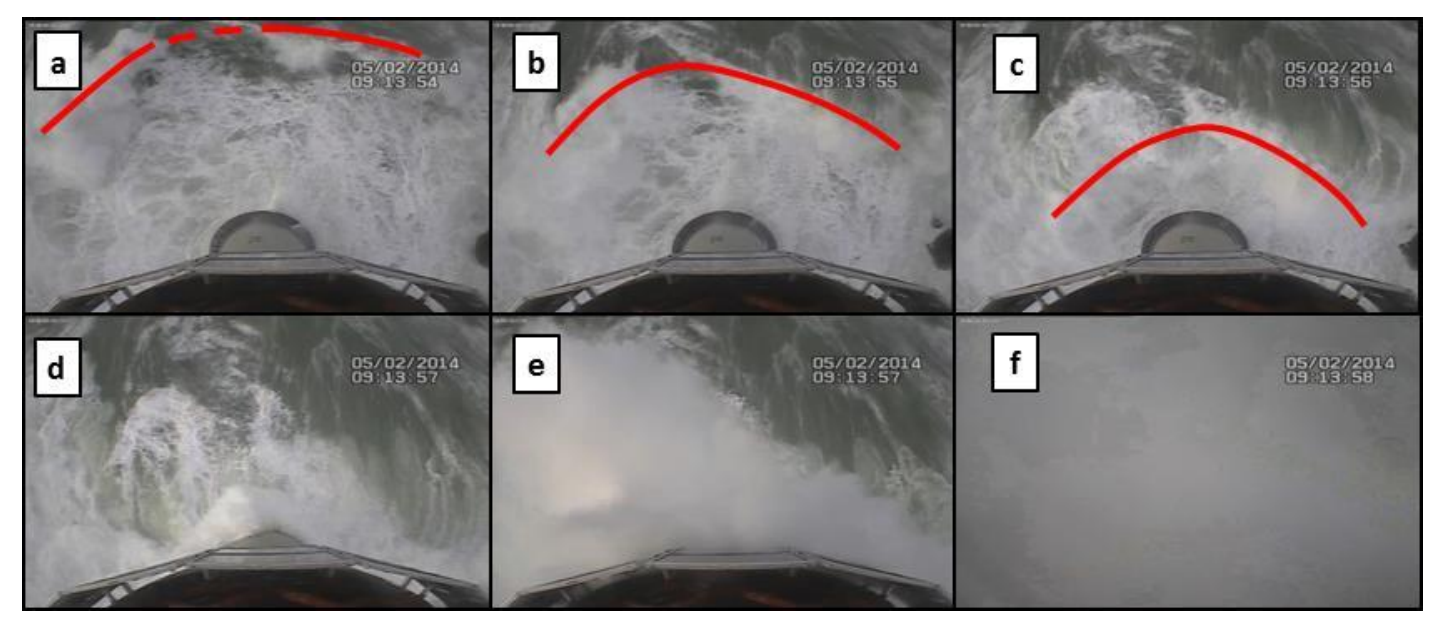

Figure 2 - Time sequence of impact at approximately $1 \mathrm{~s}$ intervals: (a) to (c) show the effect of wave refraction on the incoming wave, causing the wavefront (indicated by a red line) to become increasingly concave (and broken) as it heads into shallower water, (d) is close to the moment of impact, (e) shows the resulting wave runup the tower and spray and at (f) the spray obliterates the cameras some $41.6 \mathrm{~m}$ above the top of the cylindrical base.

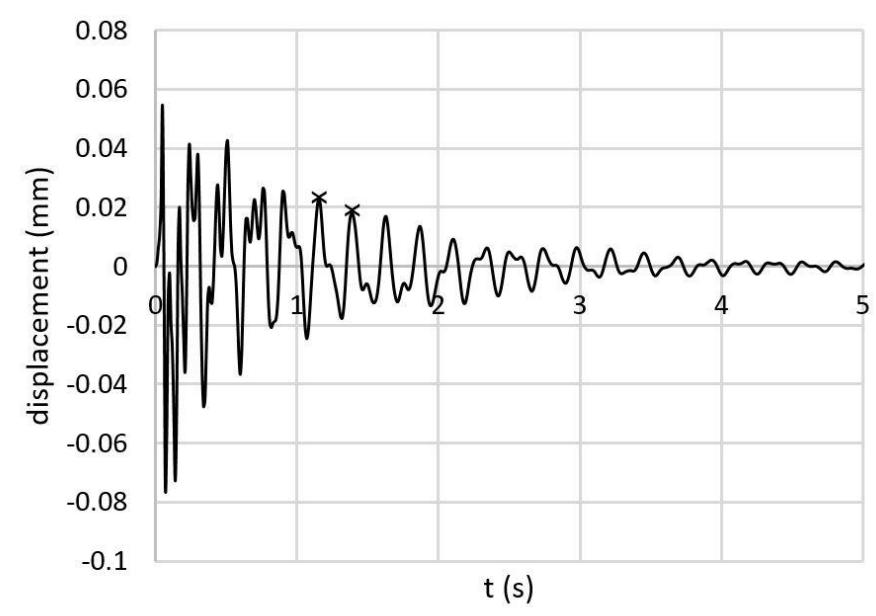

Figure 4 - Geophone displacement signal: first 5 seconds with 2 adjacent peaks highlighted to determine the damping ratio (in Section 4.3). 

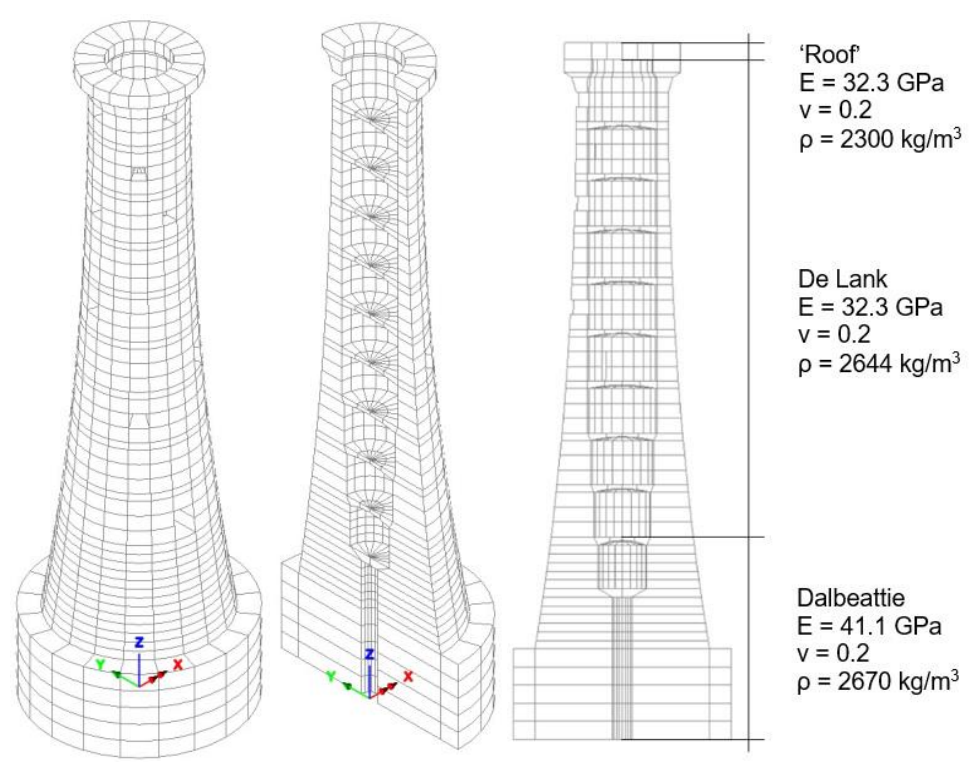

Figure 5 - Eddystone lighthouse model: (a) and (b) original model and mesh (c) modified model with fictitious roof and calibrated material properties, indicating the De Lank and Dalbeattie quarry sources.

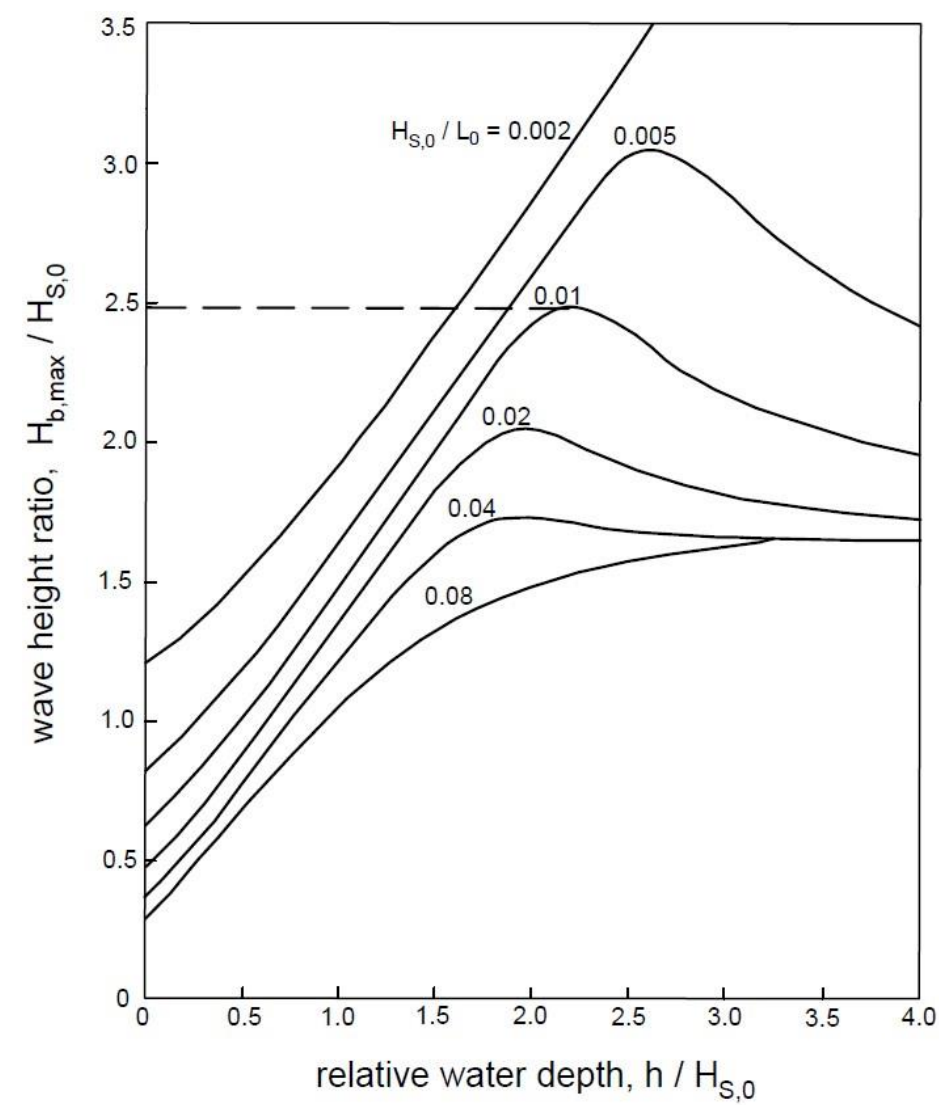

$H_{b, \max }$ for Sea Bottom Slope = 1/10 (based upon Goda (2000) [22]). 


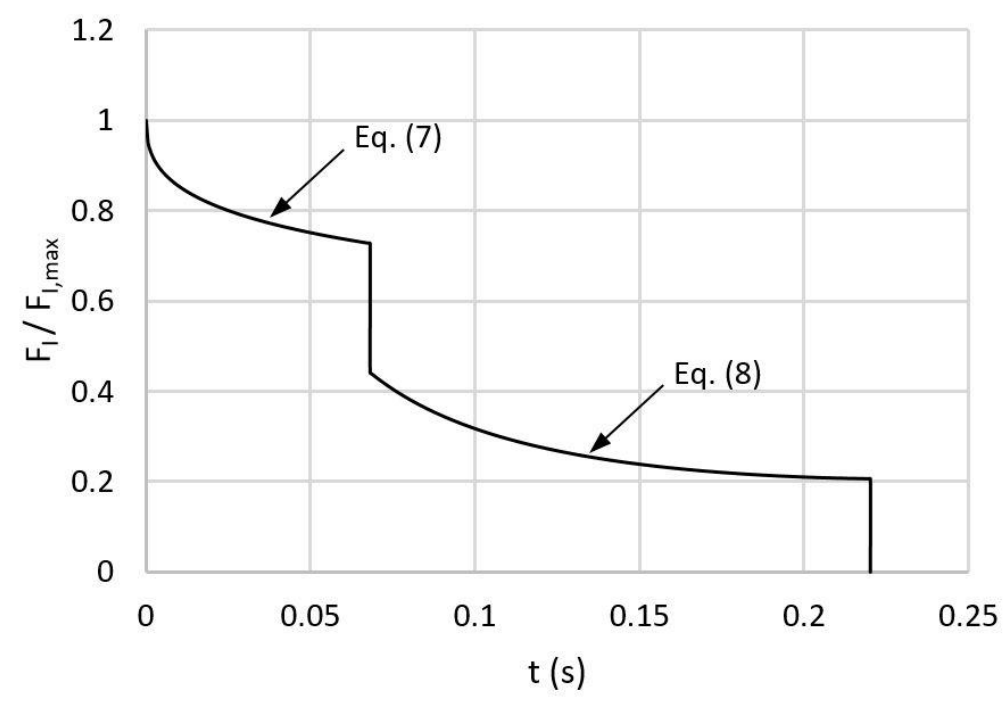

Figure 7 - Normalised load curve for the dynamic force calculated with Wienke \& Oumeraci (2005) [17].

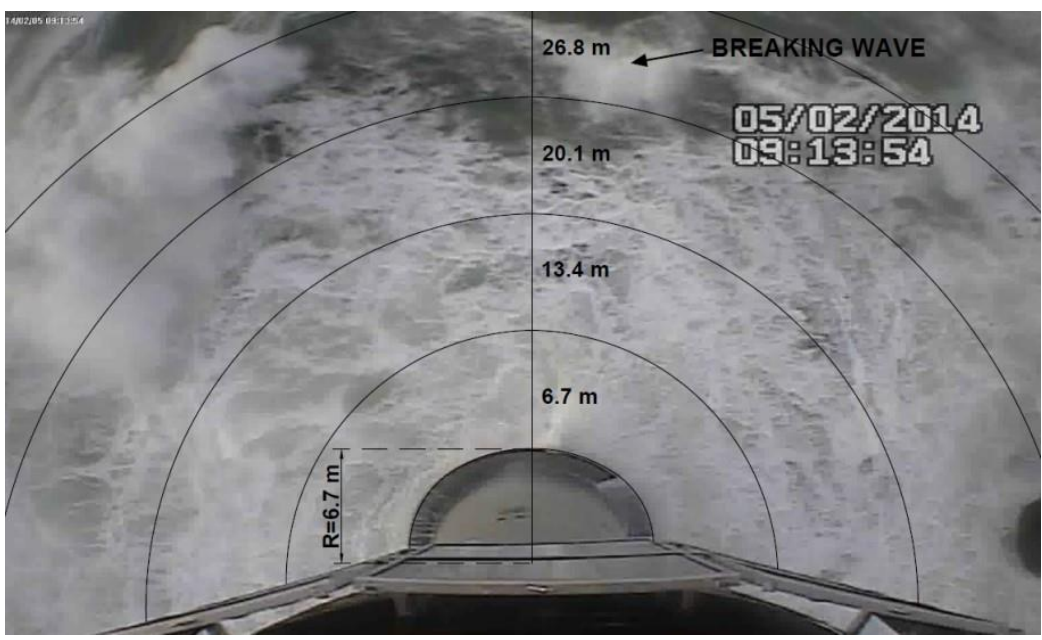

Figure 8 - Video camera image with grid: instant of wave breaking (note that concentric circles are used for simplicity for the grid, assuming there is no camera image distortion).

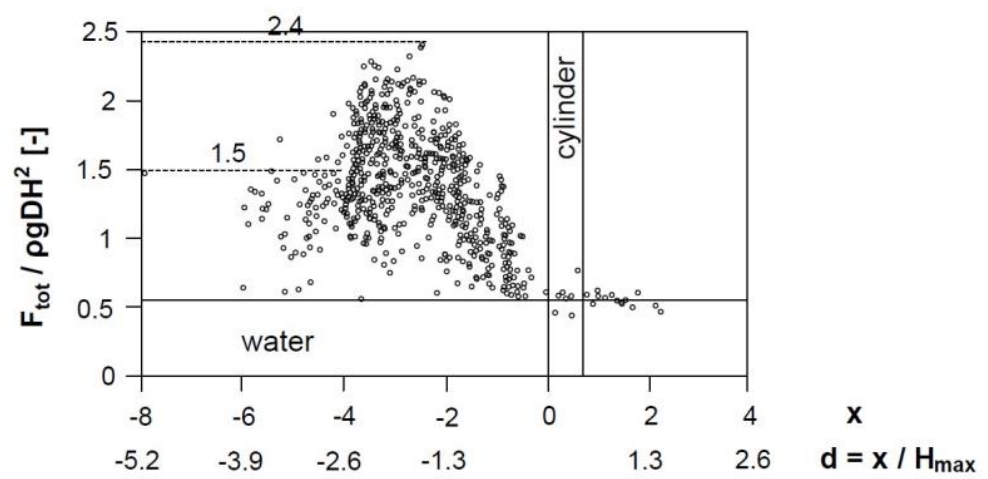

Figure 9 - Experimental results correlating breaking distance $(\mathrm{x})$ with wave load (based upon Wienke (2001) [23]). 


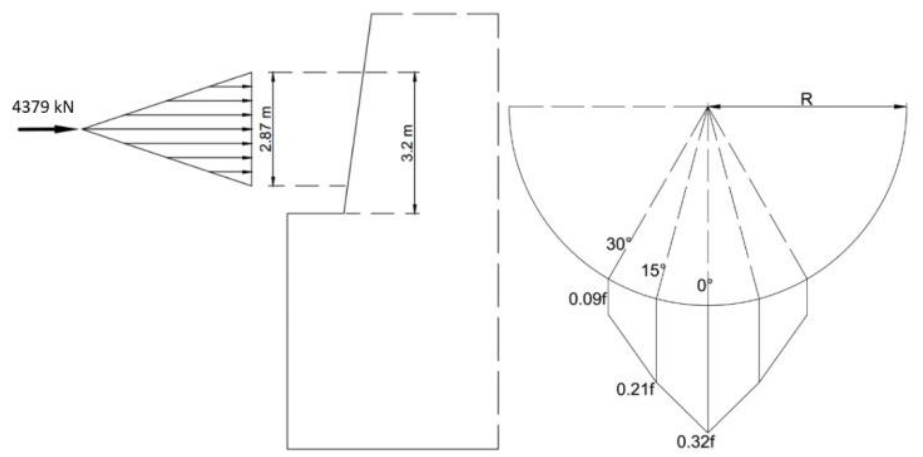

Figure 10 - Theoretical load spatial distribution: vertical distribution (left) and azimuthal distribution (right).

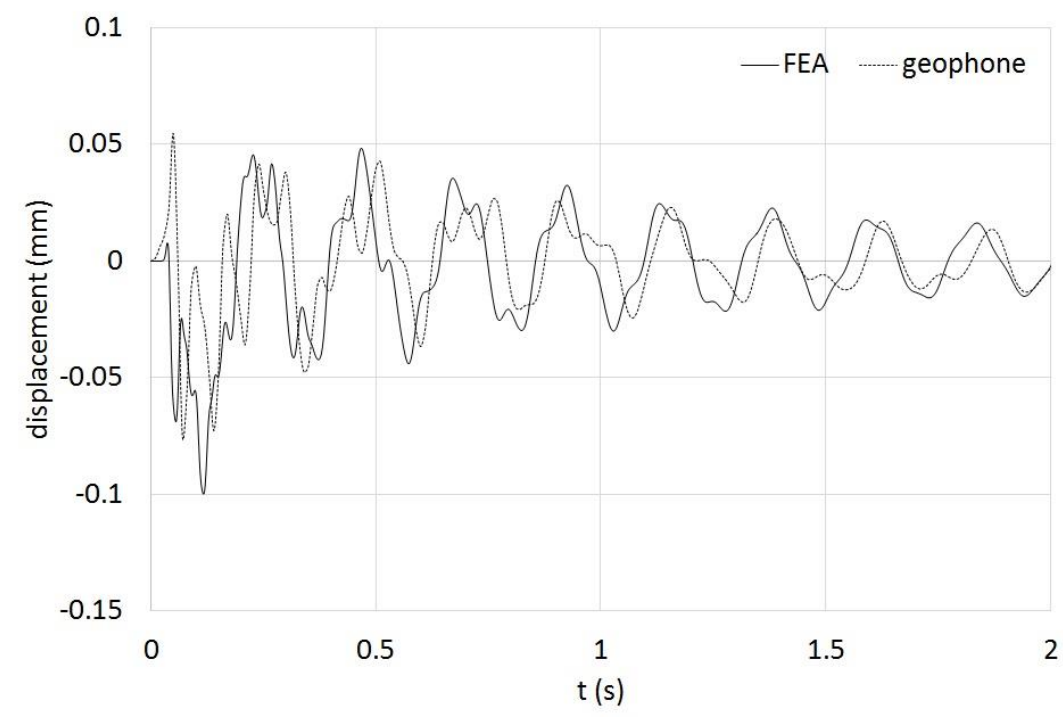

Figure 11 - Comparison between displacement histories: FEA signal (continuous) and filtered geophone signal (dashed).

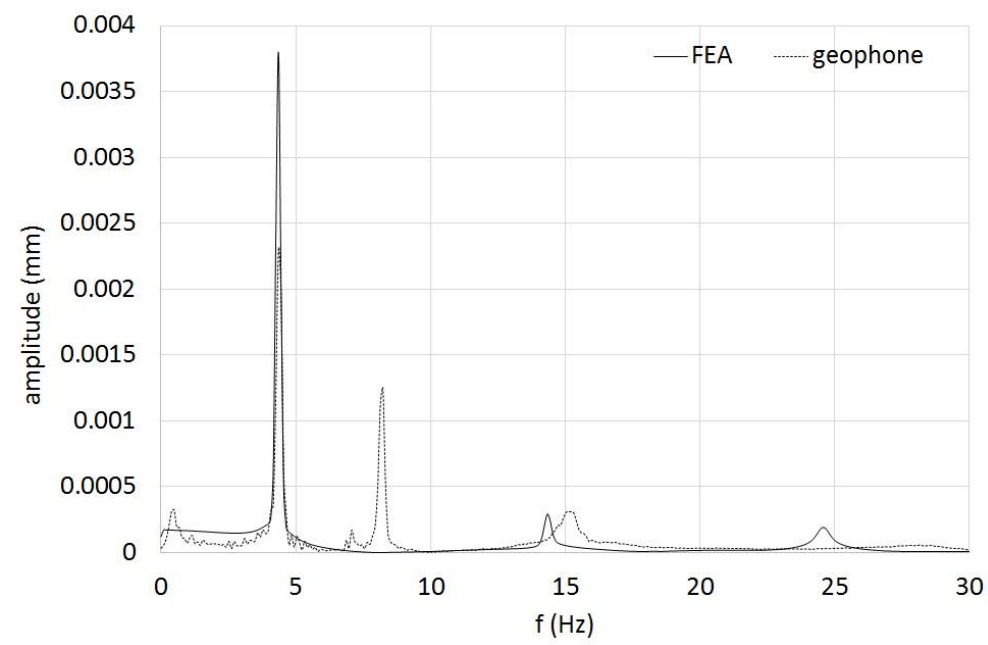

Figure 12 - Amplitude spectra of FEA (continuous) and geophone (dashed) displacements. 


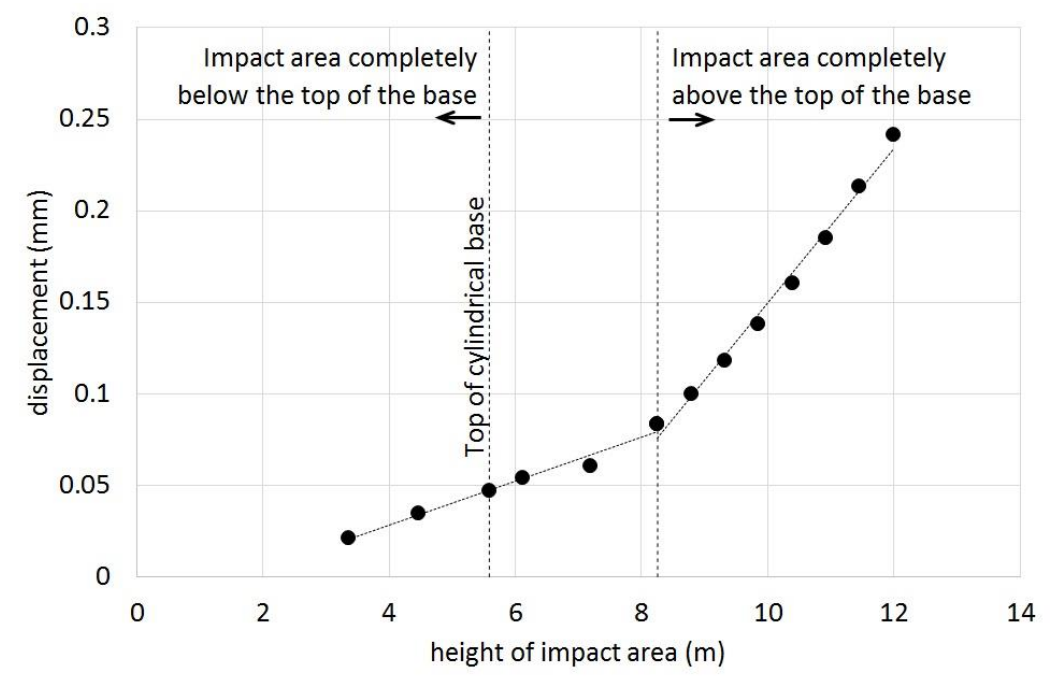

Figure 13 - Relation between maximum displacement and height of the impact area.

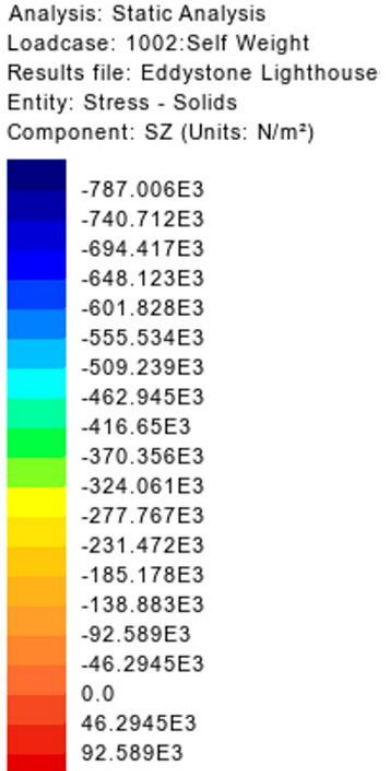

Component: SZ (Units: $\mathrm{N} / \mathrm{m}^{2}$ )

$-740.712 \mathrm{E} 3$

$-694.417 \mathrm{E} 3$

$-648.123 E 3$

$-601.828 \mathrm{E} 3$

$-555.534 \mathrm{E} 3$

$-509.239 \mathrm{E} 3$

$-462.945 \mathrm{E} 3$

$-416.65 \mathrm{E} 3$

$-370.356 \mathrm{E} 3$

$-324.061 \mathrm{E} 3$

$-277.767 \mathrm{E} 3$

$-231.472 \mathrm{E} 3$

$-185.178 \mathrm{E} 3$

$-138.883 \mathrm{E} 3$

$-92.589 \mathrm{E} 3$

$-46.2945 \mathrm{E} 3$

0.0

46.2945E3

$92.589 \mathrm{E} 3$

Maximum 128.552E3 at node 6925 Minimum -797.337E3 at node 4960

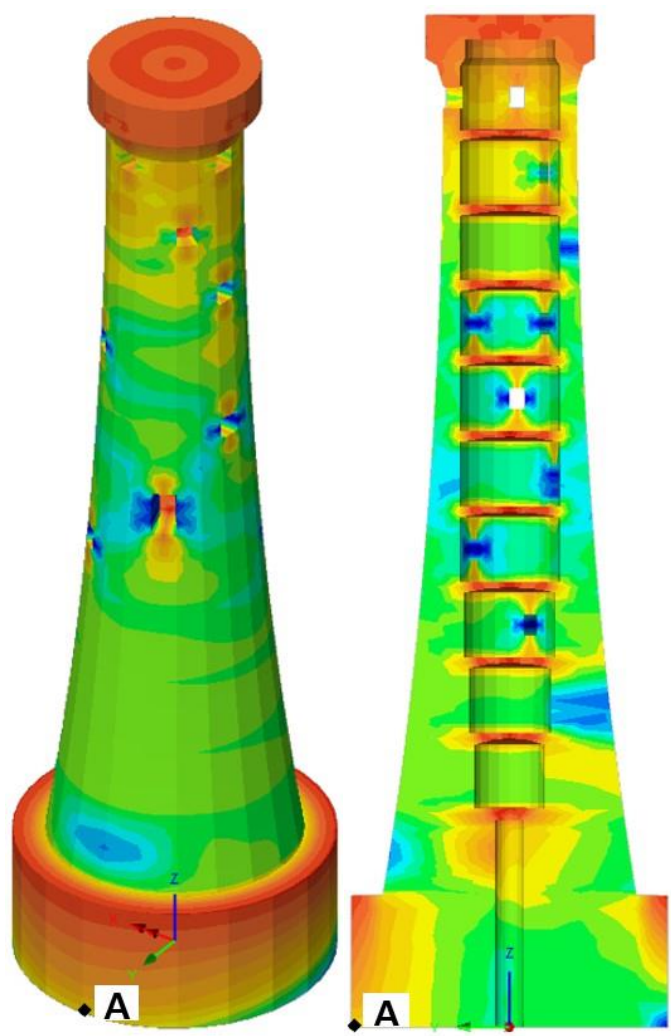

Figure 14 - Vertical normal stress distribution due to self-weight: axonometric view (left) and vertical cross section (right). 


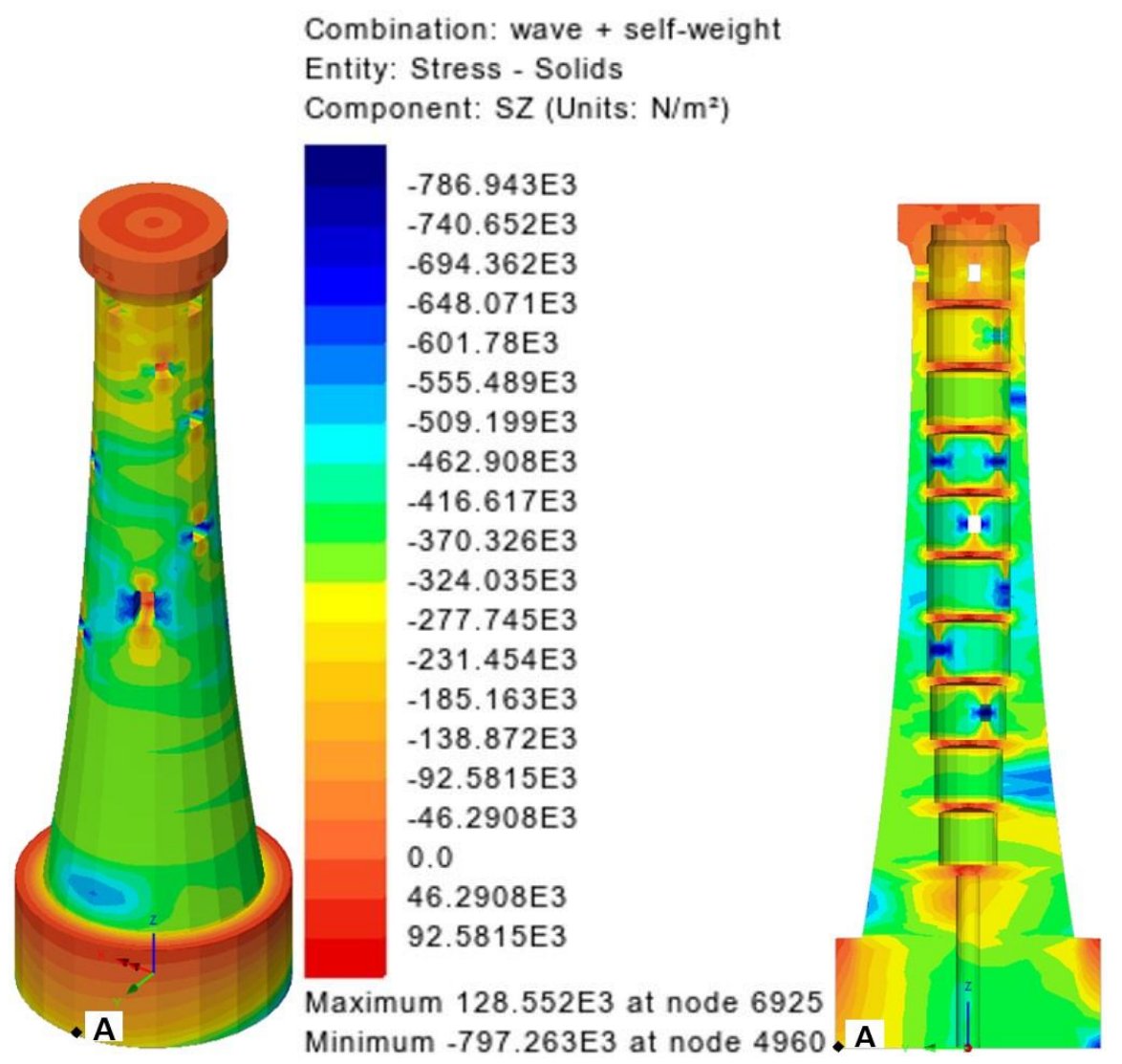

Figure 15 - Vertical stress distribution caused by combined self-weight and wave impact at $0.012 \mathrm{~s}$ : axonometric view (left) and vertical cross section (right).
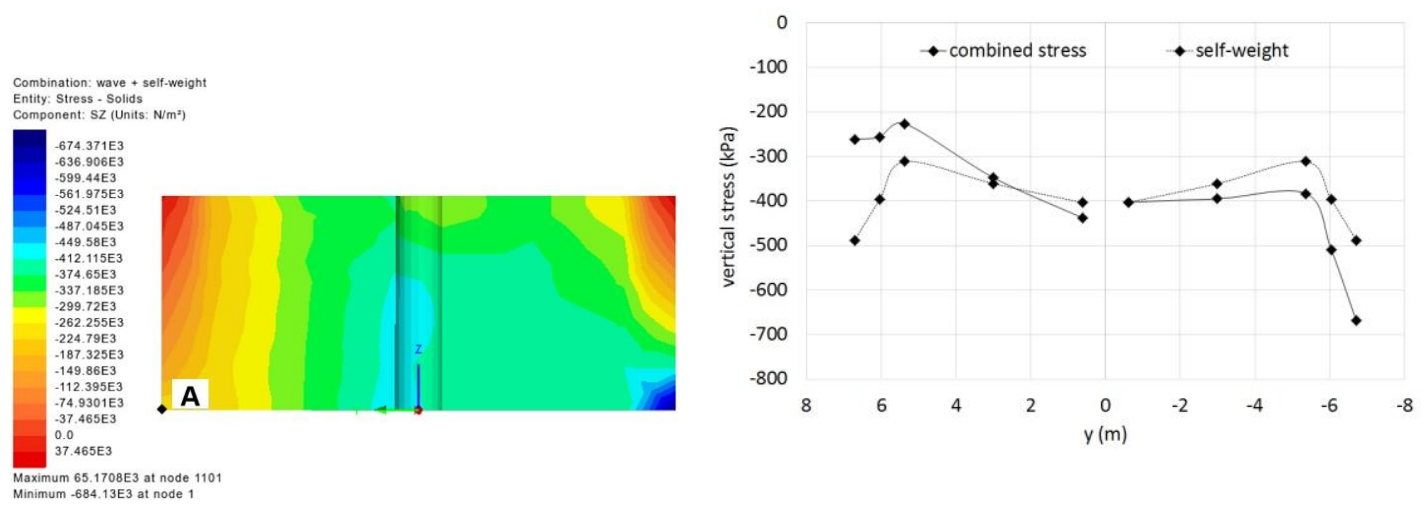

Figure 16 - Vertical stress distribution in the base caused by self-weight and wave impact at $0.012 \mathrm{~s}$. 

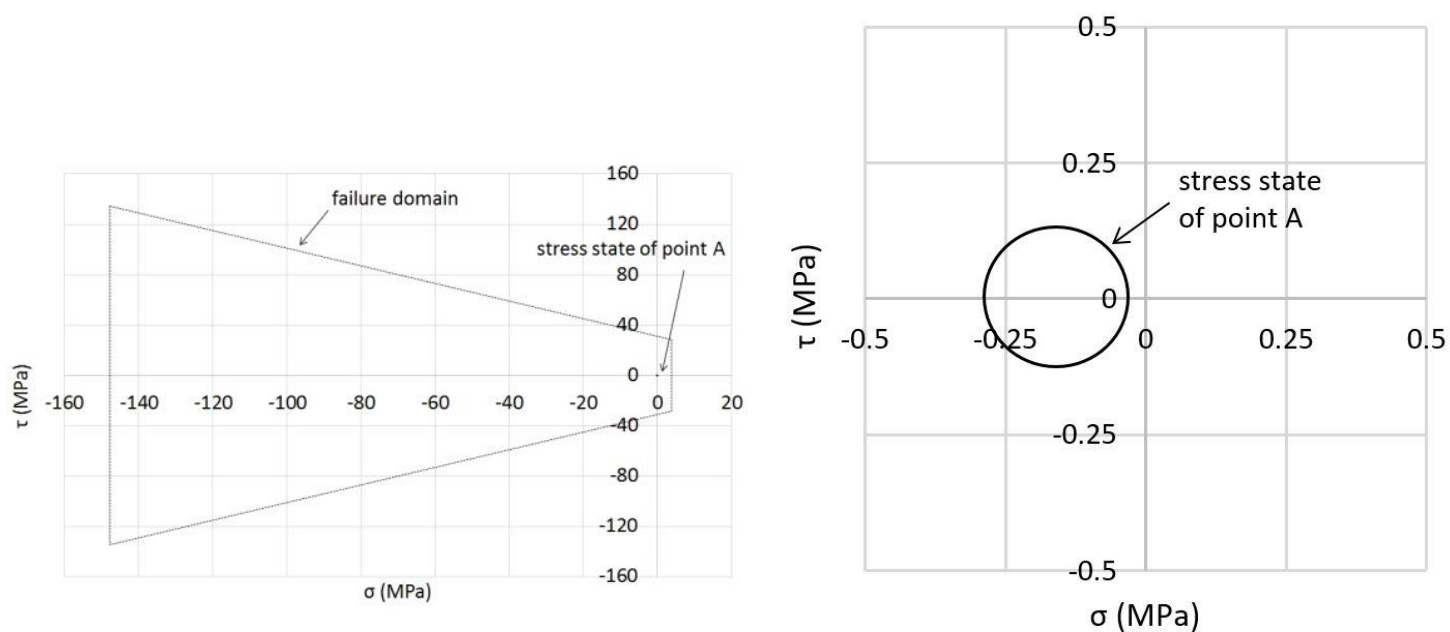

Figure 17 - Mohr-Coulomb failure criteria and stress state of point A in the Mohr diagram: full diagram (left) and zoom around the stress state of point $A$ (right).

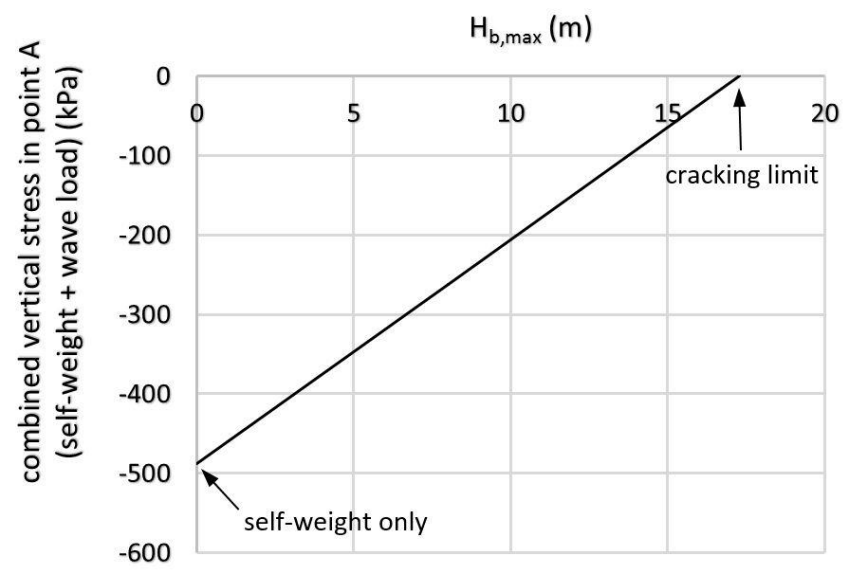

Figure 18 - Cracking Limit: combined vertical stress in point $A$ as a function of wave height.

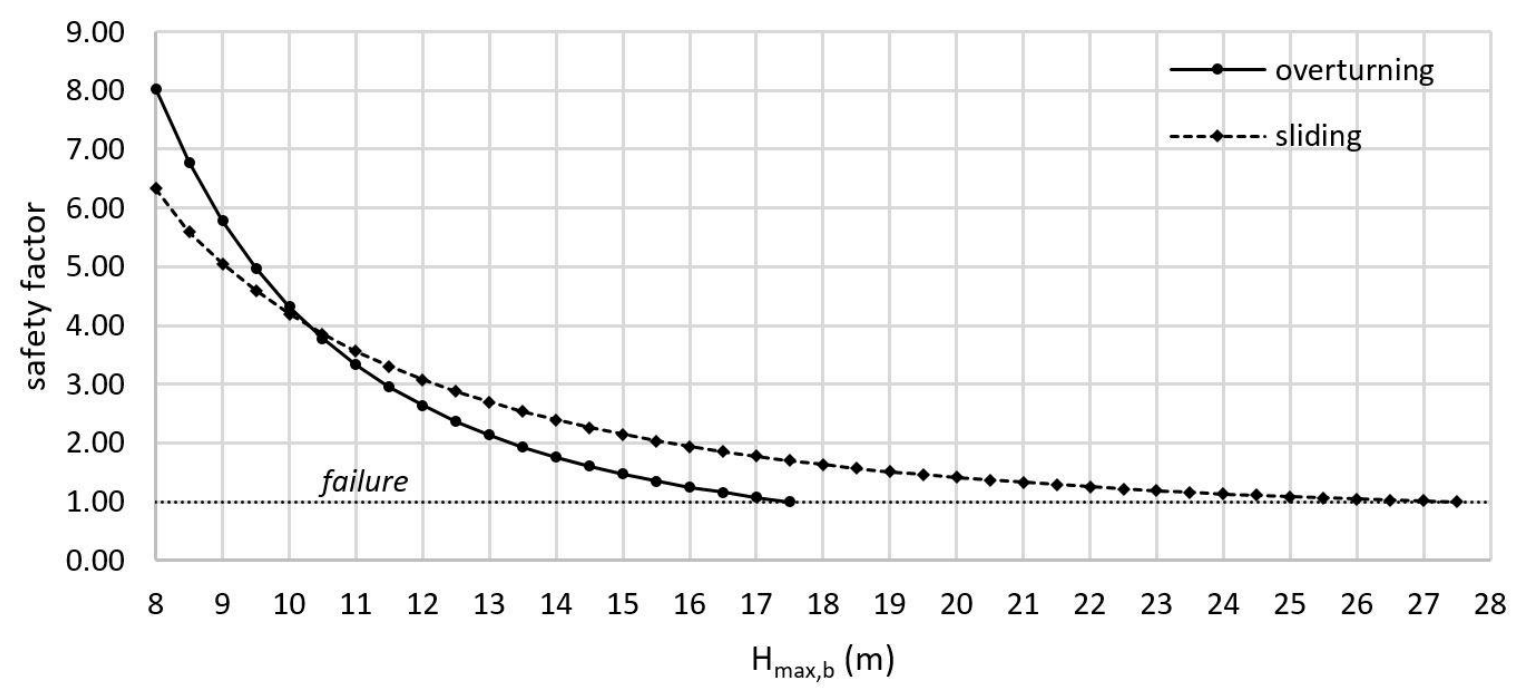

Figure 19 - Overturning and sliding: safety factor as a function of wave height. 